Original Article

\title{
An Increase in Circulating B Cell-Activating Factor in Childhood-Onset Ocular Myasthenia Gravis
}

\author{
Mitsuo Motobayashi, Yuji Inaba MD PhD*, Takafumi Nishimura, \\ Norimoto Kobayashi MD PhD, Yozo Nakazawa MD PhD, Kenichi Koike MD PhD
}

Department of Pediatrics, Shinshu University School of Medicine, Matsumoto, Japan

\begin{abstract}
BACKGROUND: Myasthenia gravis is a B cell-mediated autoimmune disorder. The pathophysiology of childhoodonset ocular myasthenia gravis remains unclear. We investigated serum B cell-activating factor levels and other immunological parameters in child patients with ocular myasthenia gravis. METHODS: Blood samples were obtained from 9 children with ocular myasthenia gravis and 20 age-matched controls. We assayed serum concentrations of $\mathrm{B}$ cell-activating factor, anti-acetylcholine receptor antibody titers, 7 types of cytokines (interleukins-2, $-4,-6,-10$, and $-17 A$; interferon- $\gamma$; tumor necrosis factor- $\alpha$ ) as well as the percentages of peripheral blood CD4+, CD8+, and CD19+ cells. RESULTS: Serum B cell-activating factor levels were significantly higher before immunosuppressive therapy in patients with childhood-onset ocular myasthenia gravis than in controls and decreased after immunosuppressive therapy. A significant positive correlation was observed between serum B cell-activating factor levels and anti-acetylcholine receptor antibody titers in patients with myasthenia gravis. Serum B cell-activating factor concentrations did not correlate with the percentages of CD4+, CD8+, and CD19+ cells or the $\mathrm{CD} 4+/ \mathrm{CD} 8+$ ratio. No significant differences were observed in the levels of the 7 different types of cytokines examined, including interleukin-17A, between preimmunosuppressive therapy myasthenia gravis patients and controls. ConcLUSIONS: Circulating B cell-activating factor may play a key role in the pathophysiology of childhood-onset ocular myasthenia gravis.
\end{abstract}

Keywords: childhood-onset ocular myasthenia gravis, B-cell activating factor, IL-17, Th17

Pediatr Neurol 2015; 52: 404-409

(C) 2015 Elsevier Inc. All rights reserved.

\section{Introduction}

B-cell activating factor (BAFF), a member of the tumor necrosis factor (TNF) superfamily, is secreted by various myeloid cells such as macrophages, dendritic cells, and neutrophils. ${ }^{1}$ BAFF is a potent survival factor for B cells and plays an essential role in peripheral Bcell homeostasis. ${ }^{2}$ The overexpression of BAFF protects B cells from apoptosis, thereby contributing to autoimmunity and malignancy. ${ }^{3-5}$ Accordingly, the BAFF pathway may be a novel target for the treatment of

\footnotetext{
Article History:

Received October 20, 2014; Accepted in final form December 24, 2014

* Communications should be addressed to: Inaba; Department of Pediatrics; Shinshu University School of Medicine; 3-1-1 Asahi; Matsumoto 390-8621, Japan.

E-mail address: inabay@shinshu-u.ac.jp
}

autoimmune diseases. The clinical application of an anti-BAFF neutralizing antibody (LymphoStat-B, Belimumab) to treat systemic lupus erythematosus has already been reported. ${ }^{6,7}$

Myasthenia gravis (MG) is a B cell-mediated autoimmune disorder in which the target autoantigen is the acetylcholine receptor (AChR) at the neuromuscular junction. Previous studies demonstrated that serum BAFF levels were significantly higher in adult patients with MG than in controls. $^{8-10}$ Childhood-onset MG is a relatively uncommon disease, with an estimated incidence of 3-9.1 per million per year, $^{11}$ and the relationship between BAFF and childhoodonset MG remains unclear.

We examined serum BAFF levels, the frequencies of peripheral blood T-cell subsets and CD19+ cells, and levels of seven types of circulating cytokines at different clinical stages in patients with childhood-onset ocular MG. 


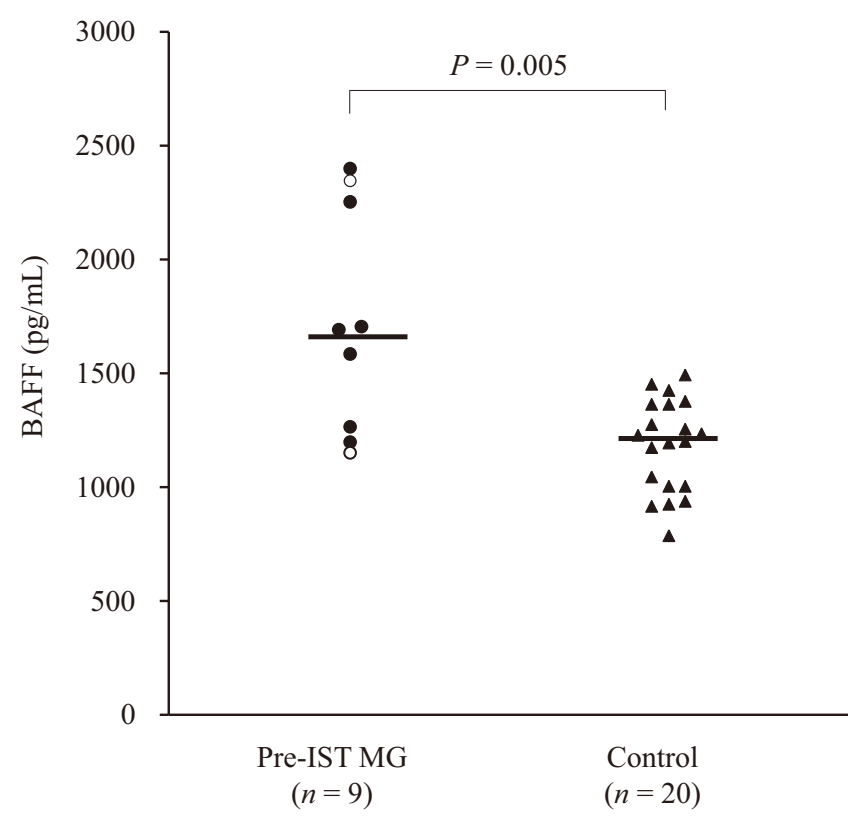

FIGURE 1.

Serum B cell-activating factor (BAFF) levels in ocular myasthenia gravis (MG) patients before immunosuppressive therapy and controls. Horizontal bars represent median values. Statistical comparisons by the Mann-Whitney $U$ test. Horizontal bars represent median values. Open circles indicate negative antiacetylcholine receptor antibody titers in pre-immunosuppressive therapy (IST) MG patients; filled circle represent positive titers.

detectable limit $(0.3 \mathrm{nmol} / \mathrm{L})$ was defined as $0.1 \mathrm{nmol} / \mathrm{L}$. All statistical analyses were conducted using PASW statistics, version 18 (SPSS Inc, Chicago, USA). The level of significance was defined as a $P$ value of less than 0.05

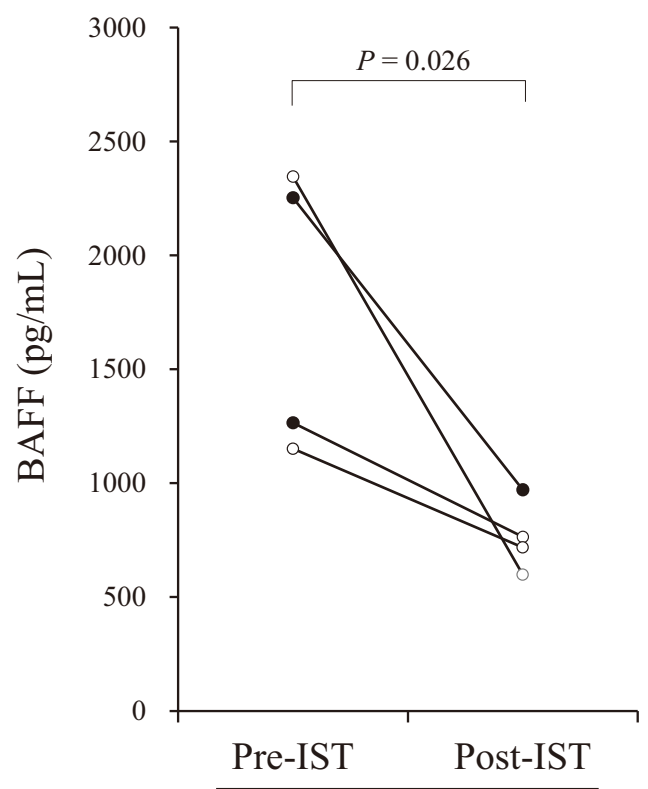

Patients with MG

FIGURE 2.

Serum B cell-activating factor (BAFF) levels in 4 patients with ocular myasthenia gravis (MG) before and after immunosuppressive therapy. Open circles indicate negative anti-acetylcholine receptor antibody titers in pre- and post-immunosuppressive therapy (IST) MG patients; filled circles represent positive titers.

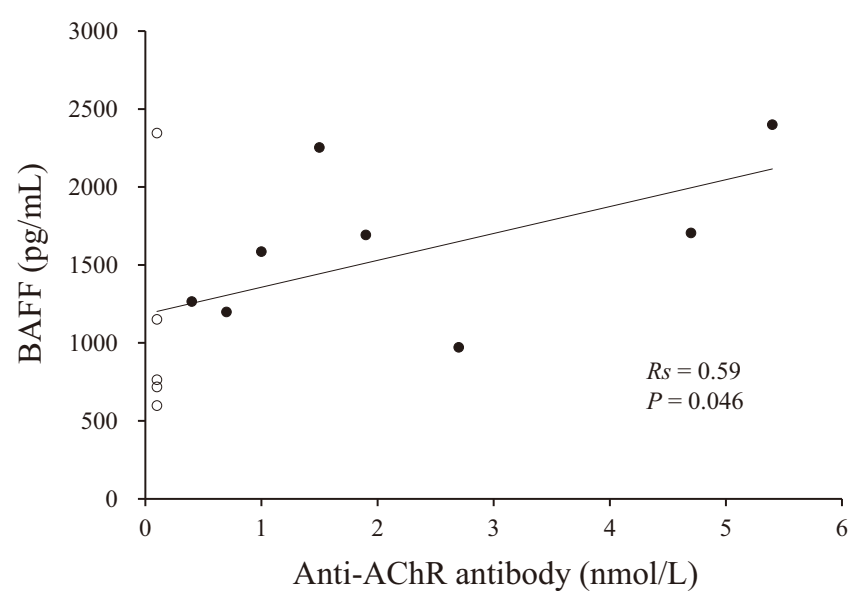

FIGURE 3.

Positive correlation between B cell-activating factor (BAFF) levels and antiacetylcholine receptor $(A C h R)$ antibodies in pediatric patients with ocular myasthenia gravis (MG). Open circles indicate negative anti-AChR antibody titers in pre- and post-immunosuppressive therapy MG patients; filled circles represent positive titers.

\section{Results}

\section{Clinical characteristics}

The clinical data of children with ocular MG are presented in Table 1 . No significant differences were observed in age, gender, or white blood cell/lymphocyte counts between the pre-IST MG group and controls. No patients had thymoma. Of the nine patients in the pre-IST MG group, three were treated with anti-cholinesterase drugs at the time of analysis. In the post-IST MG group, three patients received oral prednisolone with or without an anticholinesterase agent. The remaining patient underwent two courses of immunoadsorption plasmapheresis followed by the administration of oral prednisolone. The mean duration from the start of prednisolone therapy to immunological analysis was $36.5 \pm 12.4$ (28-55) days. Two of nine patients in pre-IST group tested negative for the anti-AChR antibody throughout their clinical course. Another one of nine patients tested positive in the pre-IST period and turned negative in the post-IST period. In total, 7 patients in the pre-IST MG group and one post-IST MG patient were positive for the anti-AChR antibody; their titers were $2.2 \pm 2.0 \mathrm{nmol} / \mathrm{L}$ and $2.7 \mathrm{nmol} / \mathrm{L}$, respectively. Serum immunoglobulin $G$ levels were significantly lower in the post-IST MG group than in the pre-IST MG group $(P=0.02)$. Additionally, the percentages of $\mathrm{CD} 4+, \mathrm{CD} 8+$, and CD19+ cells in the pre-IST MG group were not significantly different from those in the post-IST MG group.

Serum BAFF levels in children with ocular MG before and after IST

As shown in Figure 1, serum BAFF levels were significantly higher in the pre-IST MG group $(1732.7 \pm 494.7 \mathrm{pg} /$ $\mathrm{mL})$ than in the control group (1182.8 $\pm 203.5 \mathrm{pg} / \mathrm{mL}$; $P=0.005)$. Serum BAFF levels could be compared before and after IST in 4 patients and were found to be markedly decreased by IST $(P=0.026)$, as shown in Figure 2 . On the other hand, about serum anti-AChR antibody, two of four 

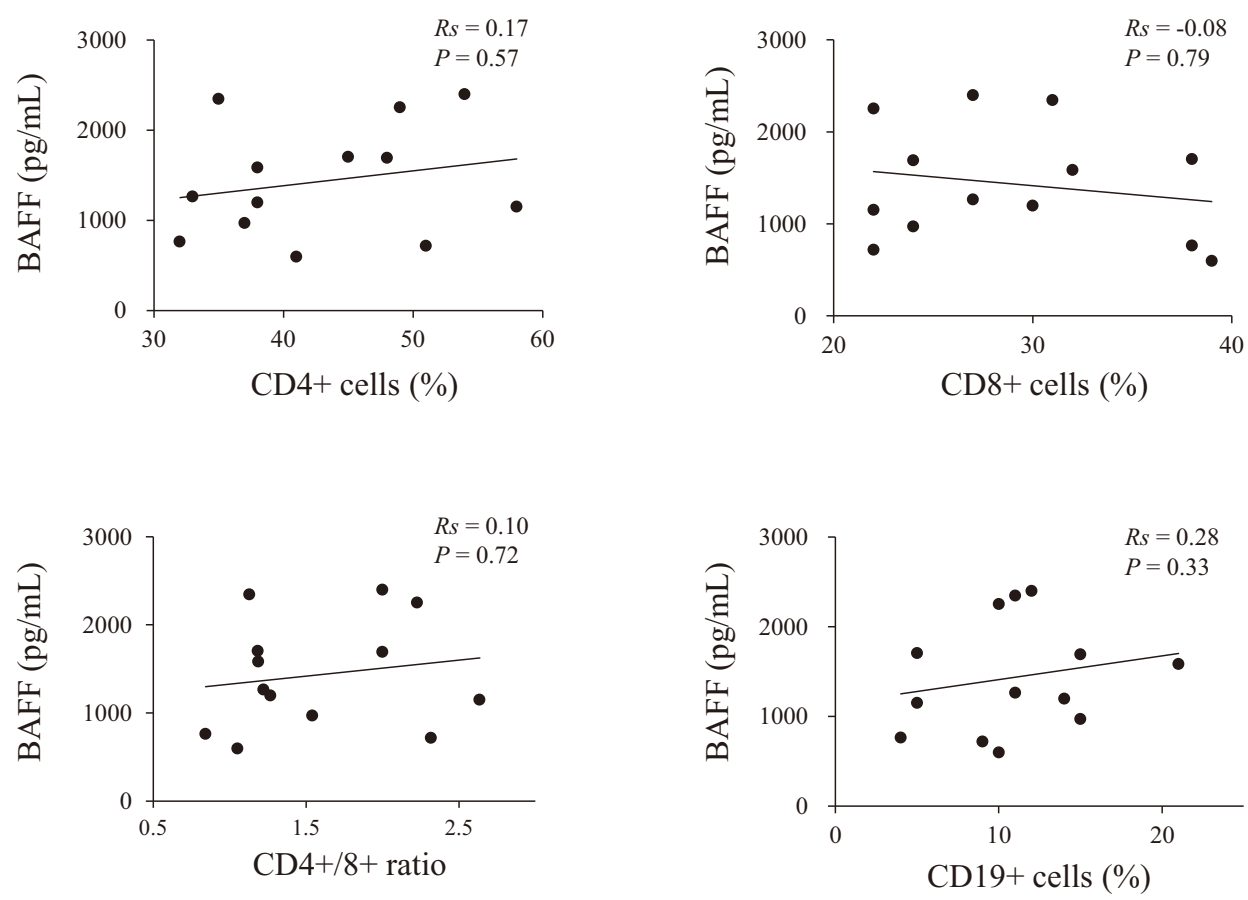

FIGURE 4.

B cell-activating factor (BAFF) levels did not correlate with the percentages of CD4+, CD8+, and CD19+ cells or the CD4+/CD8+ ratio in pediatric patients with ocular myasthenia gravis.

patients in post-IST group were seronegative, one of the seropositive patients turned seronegative after IST, and the other patient remained seropositive whose titer got higher after IST (1.5-2.7 $\mathrm{nmol} / \mathrm{L})$.

Relationship between serum BAFF levels and the humoral/cellular immune status

To determine the relationship between serum BAFF levels and the humoral/cellular immunity status, we simultaneously assessed serum anti-AChR antibody titers; the percentages of peripheral blood CD19+, CD4+, and CD8+ cells; and CD4+/CD8+ ratios in the pre- and postIST MG periods. As shown in Figure 3, a significant positive correlation was observed between serum BAFF levels and anti-AChR antibody titers in patients with MG $(R$ values $=0.59, P=0.046)$. On the other hand, serum BAFF concentrations did not correlate with the values of the four other parameters (the percentages of $\mathrm{CD} 4+, \mathrm{CD} 8+$, and CD19+ cells; and $\mathrm{CD} 4+/ \mathrm{CD} 8+$ ratio), as shown in Figure 4.

\section{Serum cytokine profiles before and after IST}

Serum cytokine profiles before and after IST are shown in Table 2. No significant differences were observed in the serum concentrations of IL-6, IL-17A, and interferon- $\gamma$ between the pre-IST MG and control groups. The levels of these cytokines became undetectable after IST. On the other hand, IL-2, IL-4, IL-10, and TNF- $\alpha$ were below detectable levels in both the pre- and post-IST periods. Serum cytokine levels did not correlate with BAFF levels (data not shown).

\section{Discussion}

Although pediatric MG shares many features with adult MG, many differences exist between the two groups. Childhood-onset MG is more likely to manifest as the ocular type with a lower rate of generalization and higher percentage of patients who are seronegative for the anti-AChR antibody. There are two reports regarding the positivity for anti-AChR antibodies in childhood-onset ocular MG: one reported 43\% $(3 / 7)^{14}$ and the other documented $80 \%(4 / 5) .{ }^{15}$ The ratio of positivity of the antibody in this study was $78 \%(7 / 9)$. Furthermore, no significant differences have been reported in the ratio of males to females in childhood, which is in contrast to the female predominance observed in adult MG. The presence of thymoma is exceedingly rare in pediatric populations. Pediatric MG also spontaneously resolves at a higher rate than

TABLE 2.

Serum Cytokine Profiles of Patients with Ocular MG

\begin{tabular}{lccc}
\hline \multirow{2}{*}{$\begin{array}{l}\text { Cytokines } \\
(\mathrm{pg} / \mathrm{mL})\end{array}$} & \multicolumn{2}{l}{ Patients With Ocular MG } & Controls $(\mathrm{n}=20)$ \\
\cline { 2 - 3 } & Pre-IST $(\mathrm{n}=9)$ & Post-IST $(\mathrm{n}=4)$ & \\
\hline IL-2 & ND & ND & $1.80 \pm 1.19$ \\
IL-4 & ND & ND & ND \\
IL-6 & ND & ND & $5.39 \pm 14.70$ \\
IL-10 & $5.22 \pm 8.39$ & ND & ND \\
IL-17A & ND & ND & $14.91 \pm 18.59$ \\
TNF- $\alpha$ & $1.59 \pm 1.77$ & ND & ND \\
IFN- $\gamma$ & & $1.29 \pm 1.30$ \\
Abbreviations: & & & \\
IL $=$ Interleukin & & \\
IFN $=$ Interferon & & \\
IST $=$ Immunosuppressive treatment & & \\
MG $=$ Myasthenia gravis & & \\
ND $=$ All samples were below the detectable limit & \\
TNF $=$ Tumor necrosis factor & & \\
\hline
\end{tabular}


adult MG. ${ }^{12,15-19}$ Nevertheless, immunological differences between childhood-onset and adult MG remain unclear.

Recent studies reported the importance of BAFF in the homeostasis and functions of B cells. In animal models, the overexpression of BAFF led to the development of several autoimmune abnormalities such as hypergammaglobulinemia, B-cell hyperplasia, and a disease resembling certain aspects of systemic lupus erythematosus. ${ }^{3,4}$ Additionally, increased levels of serum BAFF have been detected in patients with autoimmune disorders including systemic lupus erythematosus, rheumatoid arthritis, Sjögren syndrome, Wegener granulomatosis, and adult MG. ${ }^{4,8,20-22}$ Thus, BAFF appears to protect autoreactive B cells from apoptosis and contribute to the development of autoimmune diseases. ${ }^{9,23,24}$ On the other hand, circulating BAFF kinetics have not been reported in childhood-onset MG. In the present study, serum BAFF levels were significantly higher before IST in children with ocular MG than in controls; these decreased after IST. Furthermore, a positive correlation was observed between serum BAFF levels and anti-AChR antibody titers. These results are consistent with previous findings obtained from adult MG patients. ${ }^{8-10}$ Thus, BAFF may play a key role in the pathogenesis of pediatric MG as well as adult MG. In addition, BAFF could be surrogate marker for therapeutic effect.

Previous studies demonstrated that the production of the anti-AChR antibody was T cell-dependent in MG. ${ }^{25-29}$ Th17, a new T-helper subset, is considered to play an important role in the pathophysiology of MG. Mu et al. reported that the percentage of Th17 cells to CD4+ cells increased with disease progression and was accompanied by the up-regulation of IL-17 in animal models of autoimmune MG. ${ }^{30}$ Zheng et al. showed that serum levels of IL-17 were significantly higher in adult patients with MG than in controls. They also demonstrated a positive correlation between circulating IL-17 values and anti-AChR antibody titers in adult MG subjects. ${ }^{31}$ Th17 cells affect the production of autoantibodies by influencing the Th1 and Th2 cytokine balance in MG patients. ${ }^{32}$ IL-17 has been shown to synergize with BAFF to promote the survival and maturation of human B cells. ${ }^{33,34}$ In this study, no significant difference was observed in the serum levels of IL-17A between pediatric MG patients in the pre-IST period and control subjects, which differed from that in adult MG patients. ${ }^{31,35}$ These results suggest an apparent difference in immunological backgrounds between pediatric and adult MG. The absence of coincident increases in serum BAFF and IL-17A levels may be related to negative or low anti-AChR antibody titers in childhood-onset ocular MG.

In conclusion, serum BAFF levels were higher before IST in patients with childhood-onset ocular MG than in the controls and decreased after IST. A positive correlation was observed between serum BAFF levels and anti-AChR antibody titers. These results suggest that BAFF may play a key role in the pathophysiology of childhood-onset ocular MG.

The authors deeply appreciate the technical assistance with measuring cytokine levels by Mr. Susumu Ito (Division of Instrumental Analysis of the Research Center for Human and Environmental Sciences, Shinshu University). The authors have no potential conflicts of interest to disclose.

\section{References}

1. Moore PA, Belvedere O, Orr A, et al. BLyS: member of the tumor necrosis factor family and B lymphocyte stimulator. Science. 1999; 285:260-263.

2. Berrih-Aknin S, Ragheb S, Le Panse R, Lisak RP. Ectopic germinal centers, BAFF and anti-B-cell therapy in myasthenia gravis. Autoimmun Rev. 2013;12:885-893.

3. Khare SD, Sarosi I, Xia XZ, et al. Severe B cell hyperplasia and autoimmune disease in TALL-1 transgenic mice. Proc Natl Acad Sci U S A. 2000;97:3370-3375.

4. Mackay F, Woodcock SA, Lawton P, et al. Mice transgenic for BAFF develop lymphocytic disorders along with autoimmune manifestations. J Exp Med. 1999;190:1697-1710.

5. Rodig SJ, Shahsafaei A, Li B, Mackay CR, Dorfman DM. BAFF-R, the major B cell-activating factor receptor, is expressed on most mature B cells and B-cell lymphoproliferative disorders. Hum Pathol. 2005; 36:1113-1119.

6. Espinosa G, Cervera R. Belimumab, a BLyS-specific inhibitor for the treatment of systemic lupus erythematosus. Drugs Today (Barc). 2010;46:891-899.

7. Stohl W, Scholz JL, Cancro MP. Targeting BLyS in rheumatic disease: the sometimes-bumpy road from bench to bedside. Curr Opin Rheumatol. 2011;23:305-310.

8. Kim JY, Yang Y, Moon JS, et al. Serum BAFF expression in patients with myasthenia gravis. J Neuroimmunol. 2008;199:151-154.

9. Ragheb S, Lisak R, Lewis R, Van Stavern G, Gonzales F, Simon K. A potential role for B-cell activating factor in the pathogenesis of autoimmune myasthenia gravis. Arch Neurol. 2008;65: 1358-1362.

10. Scuderi F, Alboini PE, Bartoccioni E, Evoli A. BAFF serum levels in myasthenia gravis: effects of therapy. J Neurol. 2011;258: 2284-2285.

11. McGrogan A, Sneddon S, de Vries CS. The incidence of myasthenia gravis: a systematic literature review. Neuroepidemiology. 2010;34: 171-183.

12. Chiang LM, Darras BT, Kang PB. Juvenile myasthenia gravis. Muscle Nerve. 2009;39:423-431.

13. Jaretzki III A, Barohn RJ, Ernstoff RM, et al. Myasthenia gravis: recommendations for clinical research standards. Task Force of the Medical Scientific Advisory Board of the Myasthenia Gravis Foundation of America. Neurology. 2000;55:16-23.

14. Lindner A, Schalke B, Toyka KV. Outcome in juvenile-onset myasthenia gravis: a retrospective study with long-term follow-up of 79 patients. J Neurol. 1997;244:515-520.

15. Evoli A, Batocchi AP, Bartoccioni E, Lino MM, Minisci C, Tonali P. Juvenile myasthenia gravis with prepubertal onset. Neuromuscul Disord. 1998;8:561-567.

16. Finnis MF, Jayawant S. Juvenile myasthenia gravis: a paediatric perspective. Autoimmune Dis. 2011;2011:404101.

17. Shinomiya N, Nomura Y, Segawa M. A variant of childhood-onset myasthenia gravis: HLA typing and clinical characteristics in Japan. Clin Immunol. 2004;110:154-158.

18. Pineles SL, Avery RA, Moss HE, et al. Visual and systemic outcomes in pediatric ocular myasthenia gravis. Am J Ophthalmol. 2010;150: 453-459 e3.

19. Haliloglu G, Anlar B, Aysun S, et al. Gender prevalence in childhood multiple sclerosis and myasthenia gravis. J Child Neurol. 2002;17: 390-392.

20. Cheema GS, Roschke V, Hilbert DM, Stohl W. Elevated serum B lymphocyte stimulator levels in patients with systemic immunebased rheumatic diseases. Arthritis Rheum. 2001;44:1313-1319.

21. Mariette X, Roux S, Zhang J, et al. The level of BLyS (BAFF) correlates with the titre of autoantibodies in human Sjogren's syndrome. Ann Rheum Dis. 2003;62:168-171.

22. Zhang J, Roschke V, Baker KP, et al. Cutting edge: a role for $\mathrm{B}$ lymphocyte stimulator in systemic lupus erythematosus. J Immunol. 2001;166:6-10.

23. Cyster JG, Hartley SB, Goodnow CC. Competition for follicular niches excludes self-reactive cells from the recirculating B-cell repertoire. Nature. 1994;371:389-395.

24. Thien M, Phan TG, Gardam S, et al. Excess BAFF rescues self-reactive B cells from peripheral deletion and allows them to enter forbidden follicular and marginal zone niches. Immunity. 2004;20:785-798. 
25. Wang ZY, Karachunski PI, Howard Jr JF, Conti-Fine BM. Myasthenia in SCID mice grafted with myasthenic patient lymphocytes: role of CD4+ and CD8+ cells. Neurology. 1999;52:484-497.

26. Kaul R, Shenoy M, Goluszko E, Christadoss P. Major histocompatibility complex class II gene disruption prevents experimental autoimmune myasthenia gravis. J Immunol. 1994;152:3152-3157.

27. Nath A, Kerman RH, Novak IS, Wolinsky JS. Immune studies in human immunodeficiency virus infection with myasthenia gravis: a case report. Neurology. 1990;40:581-583.

28. Hohlfeld R, Kalies I, Ernst M, Ketelsen UP, Wekerle H. T-lymphocytes in experimental autoimmune myasthenia gravis. Isolation of T-helper cell lines. J Neurol Sci. 1982;57:265-280.

29. Hohlfeld R, Toyka KV, Heininger K, Grosse-Wilde H, Kalies I. Autoimmune human T lymphocytes specific for acetylcholine receptor. Nature. 1984;310:244-246.

30. Mu L, Sun B, Kong Q et al. Disequilibrium of T helper type 1, 2 and 17 cells and regulatory $\mathrm{T}$ cells during the development of experimental autoimmune myasthenia gravis. Immunology. 2009; 128:e826-e836.

31. Zheng S, Dou C, Xin N, et al. Expression of interleukin-22 in myasthenia gravis. Scand J Immunol. 2013;78:98-107.

32. Masuda M, Matsumoto M, Tanaka S, et al. Clinical implication of peripheral CD $4+\mathrm{CD} 25+$ regulatory $\mathrm{T}$ cells and Th17 cells in myasthenia gravis patients. J Neuroimmunol. 2010;225: 123-131.

33. Doreau A, Belot A, Bastid J, et al. Interleukin 17 acts in synergy with B cell-activating factor to influence B cell biology and the pathophysiology of systemic lupus erythematosus. Nat Immunol. 2009; 10:778-785.

34. Ragheb S, Lisak RP. B-cell-activating factor and autoimmune myasthenia gravis. Autoimmune Dis. 2011;2011:939520.

35. Uzawa A, Kawaguchi N, Himuro K, Kanai T, Kuwabara S. Serum cytokine and chemokine profiles in patients with myasthenia gravis. Clin Exp Immunol. 2014;176:232-237. 